\title{
The statistical upper mantle assemblage
}

\author{
Anders Meibom ${ }^{\mathrm{a}, *}$, Don L. Anderson ${ }^{\mathrm{b}}$ \\ a Geological and Environmental Sciences, 320 Lomita Mall, Stanford University, Stanford, CA 94305, USA \\ b Seismological Laboratory 252-21, California Institute of Technology, Pasadena, CA 91125, USA
}

Received 19 June 2003; received in revised form 19 September 2003; accepted 9 October 2003

Dedicated to W. Jason Morgan, for his brilliant contributions to Earth Sciences.

\begin{abstract}
A fundamental challenge in modern mantle geochemistry is to link geochemical data with geological and geophysical observations. Most of the early geochemical models involved a layered mantle and the concept of geochemical reservoirs. Indeed, the two layer mantle model has been implicit in almost all geochemical literature and the provenance of oceanic island basalt (OIB) and mid-ocean ridge basalt (MORB) [van Keken et al., Annu. Rev. Earth Planet. Sci. 30 (2002) 493-525]. Large-scale regions in the mantle, such as the 'convective' (i.e. well-stirred, homogeneous) upper mantle, sub-continental lithosphere, and the lower mantle were treated as distinct and accessible geochemical reservoirs. Here we discuss evidence for a ubiquitous distribution of small- to moderate-scale (i.e. $10^{2}-10^{5}$ $\mathrm{m})$ heterogeneity in the upper mantle, which we refer to as the statistical upper mantle assemblage (SUMA). This heterogeneity forms as the result of long-term plate tectonic recycling of sedimentary and crustal components. The SUMA model does not require a convectively homogenized MORB mantle reservoir, which has become a frequently used concept in geochemistry. Recently, Kellogg et al. [Earth Planet. Sci. Lett. 204 (2002) 183-202] modeled MORB and OIB $\mathrm{Sr}$ and $\mathrm{Nd}$ isotopic compositions as local mantle averages of random distributions of depleted residues and recycled continental crustal material. In this model, homogenization of the MORB source region is achieved by convective stirring and mixing. In contrast, in the SUMA model, the isotopic compositions of MORB and OIB are the outcome of homogenization during sampling, by partial melting and magma mixing (e.g. [Helffrich and Wood, Nature 412 (2001) 501-507]), of a distribution of small- to moderate-scale upper mantle heterogeneity, as predicted by the central limit theorem. Thus, the 'SUMA' acronym also captures what we consider the primary homogenization process: sampling upon melting and averaging. SUMA does not require the participation of distinct (e.g. lower mantle) reservoirs to explain OIB compositions. The complementary methods outlined in this work and in e.g. Kellogg et al. and Helffrich and Wood, provide a strong link between geochemical data and potential geophysical observables, such as the degree of partial melting, size of the melting regime, the characteristic length scales of the chemical heterogeneity and bathymetry, seismic scattering and anisotropy. We support the view that statistical distributions of lithologic components and sampling theory should replace the concept of distinct, isolated geochemical reservoirs, and extensive convective stirring prior to sampling.
\end{abstract}

(C) 2003 Elsevier B.V. All rights reserved.

Keywords: upper mantle; heterogeneity; sampling theory; central limit theorem; MORB; OIB

* Corresponding author. Tel.: +1-650-723-2337; Fax: +1-650-724-6360.

E-mail addresses: meibom@pangea.stanford.edu (A. Meibom), dla@gps.caltech.edu (D.L. Anderson). 


\section{Introduction}

The geochemical diversity of mid-ocean ridge basalt (MORB) and oceanic island basalt (OIB) has traditionally been attributed to the existence of large-scale mantle heterogeneity, in particular to accessible reservoirs at various depths. However, reconciling the geochemical constraints for isolated, yet accessible, mantle reservoirs with geophysical observations has become an increasingly difficult task $[1,3,4]$. The roles of mantle convection and the reservoir concept require rethinking.

Basalt is produced by partial melting in the shallow mantle. The uniformity of some MORBs in terms of abundances and isotopic compositions of lithophile trace elements [4-6] and noble gases [7] has led to the widespread (but not universally adopted) notion that the source region for 'normal' MORB (N-MORB), referred to as depleted MORB mantle (DMM), is a large-scale (i.e. global), homogeneous and degassed geochemical reservoir, complementary to the continental crust. The composition of this homogeneous DMM reservoir has in many ways become the 'backbone' assumption in modern geochemistry, the hypothetical reservoir against which all oceanic basalts are compared. These include 'enriched' MORB (E-MORB) and basalts from oceanic volcanic islands, or 'hotspots', which produce OIBs that are geochemically more diverse and distinct from the established canonical N-MORB trace element and isotopic composition. OIBs have therefore, in general, been argued to be derived from mantle reservoirs that are different from the DMM in both composition and location. One proposed OIB mantle reservoir is the primitive, undegassed (lower) mantle. Often these OIB reservoirs include ancient crustal or lithospheric materials or components, including sediments (e.g. EM1, EM2, HIMU, FOZO, PREMA and C; e.g. [1,4,8-12]) that have been subducted into the lower mantle and brought back to the shallow mantle by deeprooted mantle plumes. In this way, chemical and isotopic anomalies are introduced into the otherwise convectively homogenized DMM reservoir (Fig. 1a) [1,4,9-11,13,14]. Accounting for each distinct reservoir within the framework of the large-scale structure and dynamics of the mantle, taking into consideration the integrated long-term effects of the plate tectonic cycle, the dynamics of mantle convection and the concept of mantle plumes, has taken many forms (e.g. [1,4,8-11,15]).

Here we discuss certain aspects of statistical sampling theory that can be usefully applied to the way partial melting and other sampling processes operate on a mantle containing a ubiquitous distribution of small- to moderate-scale lithologic heterogeneity (e.g. [3]). We compare $\mathrm{Pb}, \mathrm{Sr}$ and $\mathrm{Nd}$ isotopic data for oceanic basalts in five key regions, including Iceland and Hawaii (representing OIB), the East Pacific Rise (EPR), the Mid-Atlantic Ridge (MAR) and the southwest Indian Ridge (SWIR) (representing MORB from fast, slow, and ultraslow spreading ridges, respectively). We show how the effect of different sampling of small- to moderate-scale upper mantle heterogeneity is reflected in these five data sets, as predicted by the central limit theorem, and discuss the apparent homogeneity of MORB, the variability of OIB, and the differences between OIB and MORB as consequences of the way different distributions of small- and moderate-scale mantle heterogeneities in the upper mantle are sampled and averaged out during formation of these basalts. This approach complements the quantitative convective homogenization calculations of e.g. Kellogg et al. [2] and Allègre and Levin [14], and both processes can happen in parallel.

\section{Upper mantle heterogeneity}

The source region for MORB is assumed to be the upper mantle. In many models this region is defined as the mantle above the $660 \mathrm{~km}$ discontinuity $[1,4,7-9,16,17]$. Some recent models allow more variation in the depth of the depleted, homogeneous region defined as the upper mantle (e.g. $[2,18])$. Mass balance calculations show that only a small fraction of the upper mantle can have a basaltic (i.e. fertile) source composition $[3,19]$, but most of the mantle can be depleted in the large-ion lithophile elements. From the abundances of incompatible elements in the crust and 

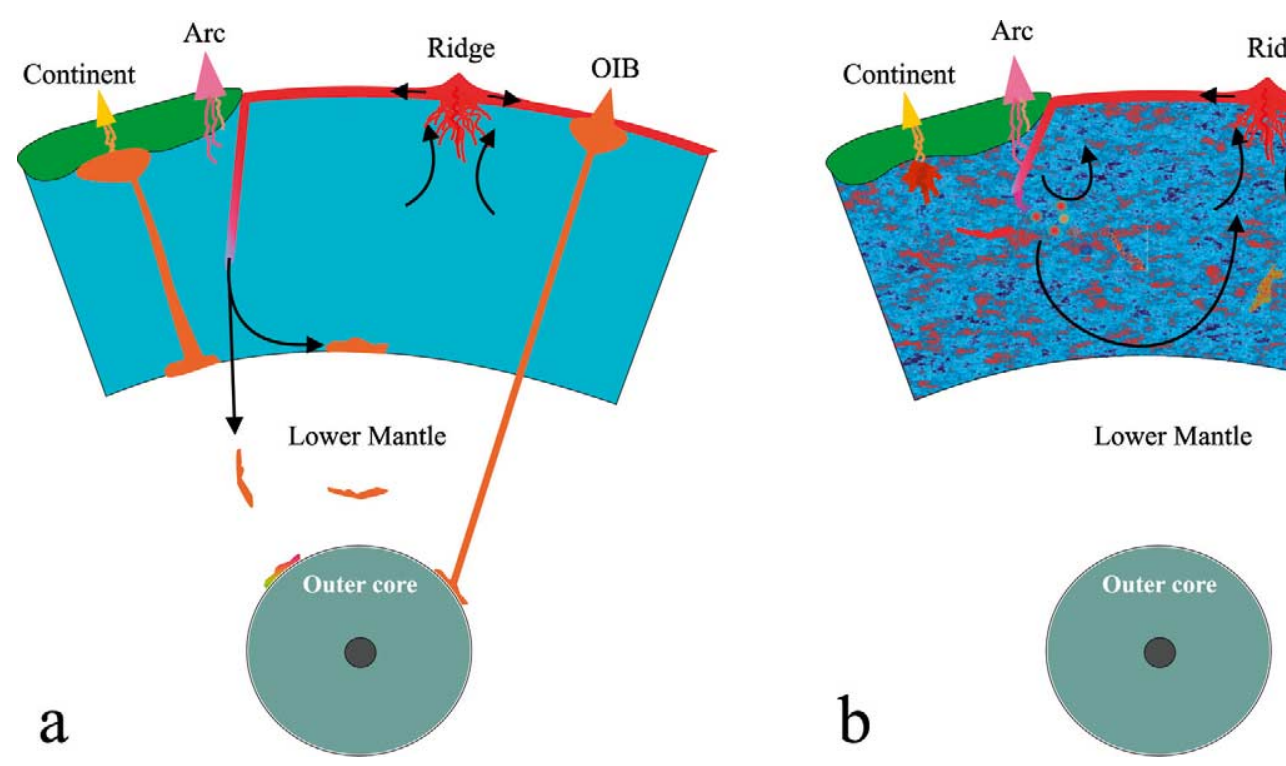

Fig. 1. Schematic illustrations (not to scale) of two contrasting views of the chemical structure of the mantle. (a) The classical, layered mantle model. As a result of vigorous convection and mixing and formation of the continental crust, the upper mantle (its size not precisely defined) is well homogenized, depleted, degassed and essentially isothermal, or adiabatic. Subducted slabs of oceanic crust and sediments (red) are convectively stirred with the depleted upper mantle reservoir (blue) on a relatively short time scale, or pass through on their way to the lower mantle. Deep subduction of slabs places some oceanic crust in the lower mantle or at the core-mantle boundary, where they age. This material can be recycled back into the upper mantle by deep-rooted mantle plumes originating at the core-mantle boundary or at a proposed thermal boundary layer in the mid-lower mantle. Deeprooted mantle plumes funnel noble gases with primordial isotopic compositions into the upper mantle from an essentially undegassed lower mantle reservoir. Adopted from Hofmann [4]. (b) The statistical upper mantle assemblage model. The upper mantle is a heterogeneous assemblage of depleted residues (bluish colors) and enriched, subducted oceanic crust, lithosphere and sediments (reddish colors). The heterogeneities are statistical in nature and have wide ranges in shape, size, age and origin. See text for discussion.

upper mantle and the ${ }^{40} \mathrm{Ar}$ content of the atmosphere, it has been inferred that partial melting has processed most, perhaps all of the mantle, not just the upper mantle (e.g. [3,19]) (Fig. 1a). It is also frequently argued that there are large unmelted or undegassed regions, or reservoirs, in the lower mantle.

Even though the properties of depleted MORB and the inferred properties of its source (DMM) often have been adopted as the properties of a homogeneous upper mantle, it is also widely recognized that the upper mantle is heterogeneous on different length scales (e.g. [1-4,10,20-25]) and an increasing number of geochemical observations continue to challenge the classical idea of a homogeneous upper mantle, including: (a) evidence for substantial heterogeneity in the abundance of volatiles (including $\mathrm{CO}_{2}$ and $\mathrm{H}_{2} \mathrm{O}$ ) in the source of MORB [26]; (b) evidence for substantial trace element heterogeneity in slightly off-axis seamounts at mid-ocean ridges and enriched-type MORB at ridges far from inferred mantle plumes, notably along the fast spreading EPR (e.g. [24,2733]); (c) extreme $\mathrm{Pb}$ isotopic heterogeneity among melt inclusions from Polynesia, spanning 50\% of the range in $\mathrm{Pb}$ isotopic composition observed for OIB world-wide [34]; (d) measurements of large isotopic heterogeneities in ${ }^{143} \mathrm{Nd} /{ }^{144} \mathrm{Nd},{ }^{87} \mathrm{Sr} /{ }^{86} \mathrm{Sr}$, ${ }^{206} \mathrm{~Pb} /{ }^{204} \mathrm{~Pb}$ and ${ }^{187} \mathrm{Os} /{ }^{188} \mathrm{Os}$ compositions in abyssal and tectonically emplaced peridotites on a variety of length scales, ranging from centimeters to tens of kilometers [35-41]. For example, the total range in ${ }^{143} \mathrm{Nd} /{ }^{144} \mathrm{Nd}$ measured over a $30 \mathrm{~km}$ length scale in rocks from the Ronda peridotite massif in Spain exceeds the total ${ }^{143} \mathrm{Nd} /{ }^{144} \mathrm{Nd}$ variation measured in OIB; (e) Substantial variation 

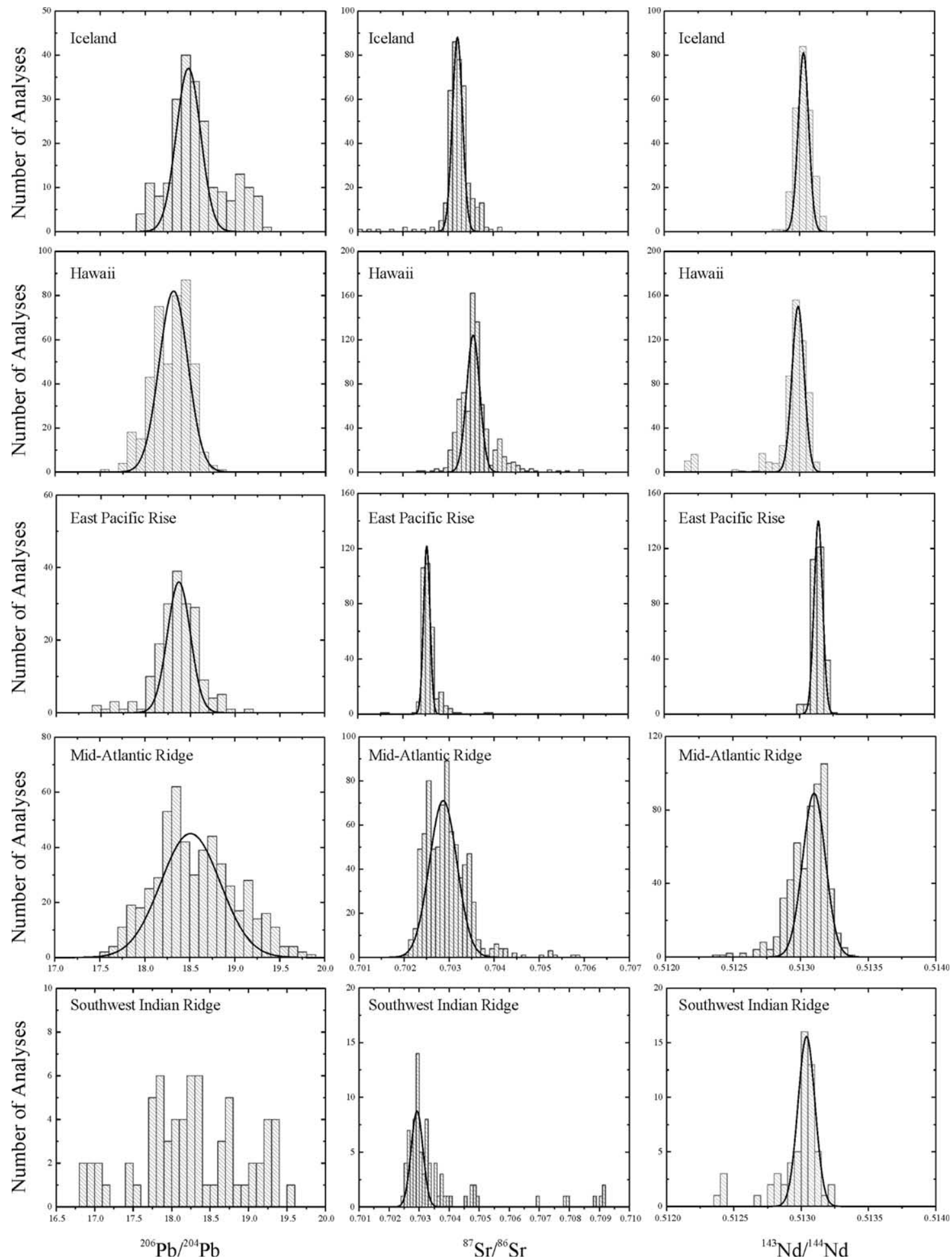
in ${ }^{3} \mathrm{He} /{ }^{4} \mathrm{He}$ isotopic compositions along a $\sim 5800$ $\mathrm{km}$ long segment of the southeast Indian Ridge (away from inferred hotspots or subduction zones) with a characteristic length scale of hundreds of kilometers [42]; and (f) large-scale, major element heterogeneity in the mantle source of the north Atlantic igneous province (e.g. [43]) and the SWIR (e.g. [44,45]). Together, these observations provide a compelling case that a very high degree of chemical and isotopic heterogeneity characterizes many regions of the upper mantle on a wide range of length scales.

However, even with the growing body of evidence for upper mantle geochemical heterogeneity, the identification of hotspot influence or plume (i.e. inferred lower mantle) components along the global spreading ridge system is often based exclusively on geochemical data by comparison to the canonical composition of 'the upper mantle' (i.e. DMM) reservoir, which is implicitly assumed to be homogeneous. We point out that the canonical composition of the DMM reservoir, based on the composition of N-MORB, is arbitrary because ridges also frequently erupt E-MORB, often in close association [24].

\section{The data}

Fig. 2 shows the statistical distributions of ${ }^{206} \mathrm{~Pb} /{ }^{204} \mathrm{~Pb},{ }^{87} \mathrm{Sr} /{ }^{86} \mathrm{Sr}$, and ${ }^{143} \mathrm{Nd} /{ }^{144} \mathrm{Nd}$ isotope ratios for basalts from Iceland, Hawaii, EPR, MAR, and SWIR. These volcanic rocks are young, with negligible radiogenic in-growth. The isotopic compositions therefore represent the isotopic composition of the source regions, under the reasonable assumption that contamination, e.g. by seawater, has not affected the data sets in any substantial or systematic way. Within each isotope system the data are binned in the same way, allowing a direct comparison between the different localities. Several important observations can be made.

All distributions are statistically symmetric. Various measures of the mean (arithmetic mean, harmonic mean, geometric mean, median) are listed in Table 1; definitions are given in the Appendix. All the measures of the mean are essentially identical for a given distribution. This test is important because the arithmetic mean of a distribution of isotope ratios, by itself, may not be a statistically robust estimator of central tendency. The medians and geometric means are the statistically appropriate measures for ratios, but these various measures do not differ significantly for our cases. If the distributions were not symmetric, the different measures of the mean would differ substantially. The skewness of each data set, a measure of the asymmetry, is small, confirming the high degree of symmetry.

For each distribution the excess kurtosis is also calculated. Excess kurtosis is a measure of the relative 'peakedness' or flatness of a distribution compared with a normal distribution, which has an inherent kurtosis value of 3 . The ${ }^{206} \mathrm{~Pb} /{ }^{204} \mathrm{~Pb}$ and ${ }^{143} \mathrm{Nd} /{ }^{144} \mathrm{Nd}$ distributions have excess kurtosis close to zero. The ${ }^{87} \mathrm{Sr} /{ }^{86} \mathrm{Sr}$ distributions have positive excess kurtosis, attributable to their slightly steeper peak shape. However, for the majority of distributions a Gaussian (solid lines in Fig. 2) provides a reasonable fit $\left(R^{2} \geq 0.75\right)$ that likely reflects the nature of the distributions (Table 1). The notable exception is the ${ }^{206} \mathrm{~Pb} /{ }^{204} \mathrm{~Pb}$ distribution for the ultraslow spreading SWIR, to which a Gaussian distribution cannot be meaningfully fitted; see discussion below. Chaotic mixing (as opposed to the type of random sampling governed by the central limit theorem; see below) typically leads to non-Gaussian distributions with excess kurtosis [46]. Reduced chi-square values $\left(\chi^{2} / v\right)$ (a measure of the deviation between the data and the Gaussian fits) are generally high,

Fig. 2. $\mathrm{Pb}, \mathrm{Sr}$, and $\mathrm{Nd}$ isotopic distributions for oceanic basalts from Iceland, Hawaii, the EPR (from $-53^{\circ}$ to $+27^{\circ}$ ), the $\mathrm{MAR}$ (from $-54^{\circ}$ to $+50^{\circ}$ ), and the SWIR (from $-54^{\circ}$ to $-24^{\circ}$ ) [45]. Data and references can be found in the databases GEOROC (http://georoc.mpch-mainz.gwdg.de/) and PETDB (http://petdb.ldeo.columbia.edu/petdb/), with data from the southern EPR added from [25]. Solid lines: fitted normal distributions. Statistical parameters derived from each distribution are listed in Table 1. See text for discussion. 
Table 1

Statistical parameters for the $\mathrm{Pb}, \mathrm{Sr}$, and $\mathrm{Nd}$ isotopic distributions of oceanic basalts from Iceland, Hawaii, EPR, MAR, and SWIR

\begin{tabular}{|c|c|c|c|c|c|c|c|c|c|c|c|c|}
\hline & $N^{\mathrm{a}}$ & Arithmetic mean* & $\begin{array}{l}\text { Harmonic } \\
\text { mean* }\end{array}$ & $\begin{array}{l}\text { Geometric } \\
\text { mean* }\end{array}$ & Median $^{\mathrm{b}}$ & $\begin{array}{l}\text { Standard } \\
\text { deviation* }\end{array}$ & Skewness* & $\begin{array}{l}\text { Excess } \\
\text { kurtosis* }\end{array}$ & Mode $^{c}$ & $\mathrm{HWHM}^{\mathrm{d}}$ & $R^{2 \mathrm{e}}$ & $\chi^{2} / v^{f}$ \\
\hline \multicolumn{13}{|c|}{${ }^{206} \mathrm{~Pb} /{ }^{204} \mathrm{~Pb}$} \\
\hline Iceland & 223 & $18.570( \pm 40)$ & 18.565 & 18.568 & 18.512 & 0.312 & 0.5 & -0.2 & 18.478 & 0.19 & 0.88 & 19.6 \\
\hline Hawaii & 434 & $18.283( \pm 19)$ & 18.281 & 18.453 & 18.321 & 0.206 & -0.4 & -0.1 & 18.313 & 0.22 & 0.86 & 78.2 \\
\hline EPR & 188 & $18.350( \pm 36)$ & 18.346 & 18.348 & 18.347 & 0.253 & -0.7 & 2.1 & 18.370 & 0.18 & 0.97 & 6.2 \\
\hline MAR & 538 & $18.571( \pm 39)$ & 18.560 & 18.780 & 18.507 & 0.466 & 0.4 & -0.1 & 18.509 & 0.47 & 0.86 & 49.2 \\
\hline \multicolumn{13}{|l|}{${ }^{87} \mathrm{Sr} /{ }^{86} \mathrm{Sr}$} \\
\hline Iceland & 390 & $0.70323( \pm 4)$ & 0.70323 & 0.70323 & 0.70322 & 0.00044 & 3.9 & 77.4 & 0.70321 & 0.00016 & 0.97 & 5.2 \\
\hline Hawaii & 770 & $0.70364( \pm 3)$ & 0.70363 & 0.70364 & 0.70358 & 0.00055 & 5.4 & 48.5 & 0.70356 & 0.00020 & 0.87 & 62.5 \\
\hline EPR & 331 & $0.70258( \pm 2)$ & 0.70258 & 0.70258 & 0.70255 & 0.00019 & 2.0 & 17.3 & 0.70253 & 0.00010 & 0.96 & 7.33 \\
\hline MAR & 767 & $0.70300( \pm 6)$ & 0.70299 & 0.70299 & 0.70290 & 0.00085 & 8.2 & 91.6 & 0.70287 & 0.00043 & 0.92 & 24.8 \\
\hline \multicolumn{13}{|c|}{${ }^{143} \mathrm{Nd} /{ }^{144} \mathrm{Nd}$} \\
\hline Iceland & 247 & $0.51303( \pm 1)$ & 0.51303 & 0.51303 & 0.51303 & 0.00006 & 0.006 & -0.1 & 0.51303 & 0.00006 & 0.99 & 2.4 \\
\hline Hawaii & 531 & $0.51293( \pm 2)$ & 0.51293 & 0.51293 & 0.51297 & 0.00019 & -3.0 & 9.0 & 0.51299 & 0.00006 & 0.98 & 44.2 \\
\hline EPR & 287 & $0.51314( \pm 1)$ & 0.51314 & 0.51314 & 0.51314 & 0.00004 & -0.7 & 1.7 & 0.51314 & 0.00004 & 0.98 & 13.2 \\
\hline MAR & 554 & $0.51306( \pm 1)$ & 0.51306 & 0.51306 & 0.51309 & 0.00013 & -1.2 & 2.7 & 0.51310 & 0.00011 & 0.87 & 131.6 \\
\hline SWIR & 58 & $0.51297( \pm 5)$ & 0.51297 & 0.51297 & 0.51303 & 0.00018 & -1.9 & 3.8 & 0.5130 & 0.00005 & 0.92 & 1.6 \\
\hline
\end{tabular}

*See Appendix for definitions. Numbers in parentheses indicate the $95 \%$ confidence intervals for the arithmetic means. n.d. $=$ not determined.

a Total number of analyses.

b Half the data of the distribution are greater or smaller than the median.

c Most frequently occurring value in the fitted normal distribution.

d Half-width-half-maximum of fitted normal distribution.

e $R^{2}$ value for fitted normal distribution.

f Reduced chi-square with $v$ degrees of freedom. 
ranging from $\sim 1.4$ to $>100$ (Table 1 ). For a nearly perfectly normally distributed data set the $\chi^{2} / v$ values would be close to 1 . The high $\chi^{2} / v$ values obtained by fitting Gaussian functions to the distributions in Fig. 2 reflect irregularities, or 'bumpiness', of the central peaks with a substantial contribution from outliers where the Gaussian fit would predict no occurrences.

The $\mathrm{Pb}$ isotopic distributions for Iceland OIB and MAR MORB have indistinguishable arithmetic means. Other regions have statistically different means and modes. The widths of the distributions from the different localities or regions are systematically different. For example, all of the EPR distributions (the fastest spreading ridge) have smaller width, or standard deviation, than the other distributions (Table 1). The widths of the distributions from Hawaii, Iceland and MAR are comparable and each spans more than half of the range in 'isotopic mantle arrays', defined by the measured ${ }^{143} \mathrm{Nd} /{ }^{144} \mathrm{Nd},{ }^{87} \mathrm{Sr} /{ }^{86} \mathrm{Sr}$, and ${ }^{206} \mathrm{~Pb} /{ }^{204} \mathrm{~Pb}$ ratios among MORB and OIB collected world-wide [4]. The SWIR distributions are generally wider than any of the other distributions. Below we discuss the significance of the shape, mean, and the systematic differences in width between the distributions in Fig. 2 in the context of the central limit theorem, which we introduce in the following.

\section{The central limit theorem}

The central limit theorem (CLT), a fundamental theorem of statistical probability, states that the distribution of sums (or averages) of a large number of independent, identically distributed variables will be approximately normally distributed, regardless of the underlying distribution.

Any physically measurable distribution has a probability function $f$ with well defined (i.e. finite) mean $(\mu)$ and standard deviation $(\sigma)$. A sequence of $n$ independent samples $\left(x_{1}, x_{2}, \ldots, x_{n}\right)$ drawn from such a distribution will have the same probability function as the underlying distribution, but its arithmetic mean, $\bar{x}=\frac{1}{n} \sum x_{i}$, will have a probability function that is the $n$-fold self-convolution of $f(\zeta)$, i.e. $f_{\bar{x}}(\zeta)=[f(\zeta)]^{* n}$, where $\zeta=x / n$. Equivalently, by the convolution theorem, the Fourier transform of the probability function of the arithmetic mean is the $n$-fold product of the Fourier transform of $f(\zeta), n F(n s): F_{\bar{x}}(s)=[n F(n s)]^{n}$ [47].

For large $n, f_{\bar{x}}(\zeta)$ will, as a consequence of the CLT, approach a normal distribution with the same mean as the underlying distribution but with a variance decreasing as $\sigma / n^{1 / 2}$ [47]. Fig. 3 illustrates the approach towards Gaussian shape after a number of self-convolutions of an underlying distribution with probability function $f(x)=$ $\mathrm{e}^{-x}$. Convergence towards Gaussian shape as a result of an increasing number of self-convolutions is independent of the nature of the probability function of the underlying distribution. This property makes the central limit theorem particularly important in geochemical sampling where the underlying distribution is not known in detail. In practice, isotopic ratios cannot be perfect normal distributions, but will approach a Gaussian depending on a number of factors, as discussed below.

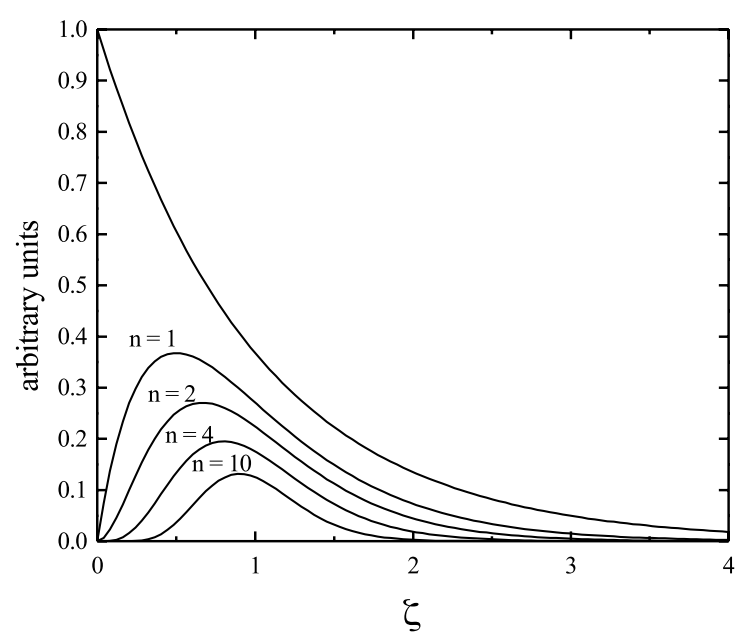

Fig. 3. Self-convolution of an exponential function $\left(f(x)=\mathrm{e}^{-x} ; x>0\right)$. The diagram illustrates the approach towards Gaussian shape and the decrease in width of successive self-convolutions [47]. The parameter ' $n$ ' denotes the number of self-convolutions. In the context of geochemical sampling $n$ is proportional to the sampled volume or the degree of partial melting. See text for discussion and definitions. 
The CLT and the concept of self-convolution are thus directly applicable to the problem of sampling chemical or isotopic heterogeneity in the upper mantle through the mixing of partial melts derived from different lithologies or depths, or the sampling of differently sized volumes of a heterogeneous distribution. The average composition of the aggregated magma is the sum of contributions from the underlying distribution of mantle heterogeneities undergoing partial melting divided by the volume of the generated magma, or of the mantle sampled (equivalent to $n$ in the above equations). In general, the larger the volume of the mantle sampled, the larger the volume of the generated magma and the smaller the variance of the compositions of magmas derived from the melt system. The Earth is more complicated in that the number of sampled heterogeneities $n$ varies within a suite of samples of basalts. In particular, a few basalts for which $n$ is small tend to produce outliers in a population where $n$ is typically much greater than 1 . This results in 'tails' in the isotopic distributions extending towards the compositions of the more fertile or enriched mantle components; this effect is most pronounced in the $\mathrm{Sr}$ isotopic distributions in Fig. 2.

Fig. 4 illustrates the power of the central limit theorem and the effectiveness with which extreme outliers are removed from an underlying distribution by one self-convolution, equivalent to increasing the degree of partial melting and/or increasing the size of the mantle domain involved in the melting process by roughly a factor of 2 . Note that the absence of outliers, extreme values or enriched samples does not imply the absence of such material in the underlying distribution. This point was also made by Kellogg et al. [2]. The corollary is that the presence of outliers in, for example, the OIB population does not require derivation from a separate reservoir. Regardless of the exact properties of the underlying distribution, a smooth distribution results from just a few convolutions, or blending of magma derived from intrinsically heterogeneous mantle lithologies. In reality, the mean, width and shape of a distribution of magma compositions from any given region within the mantle will depend upon several factors, including the exact properties of the

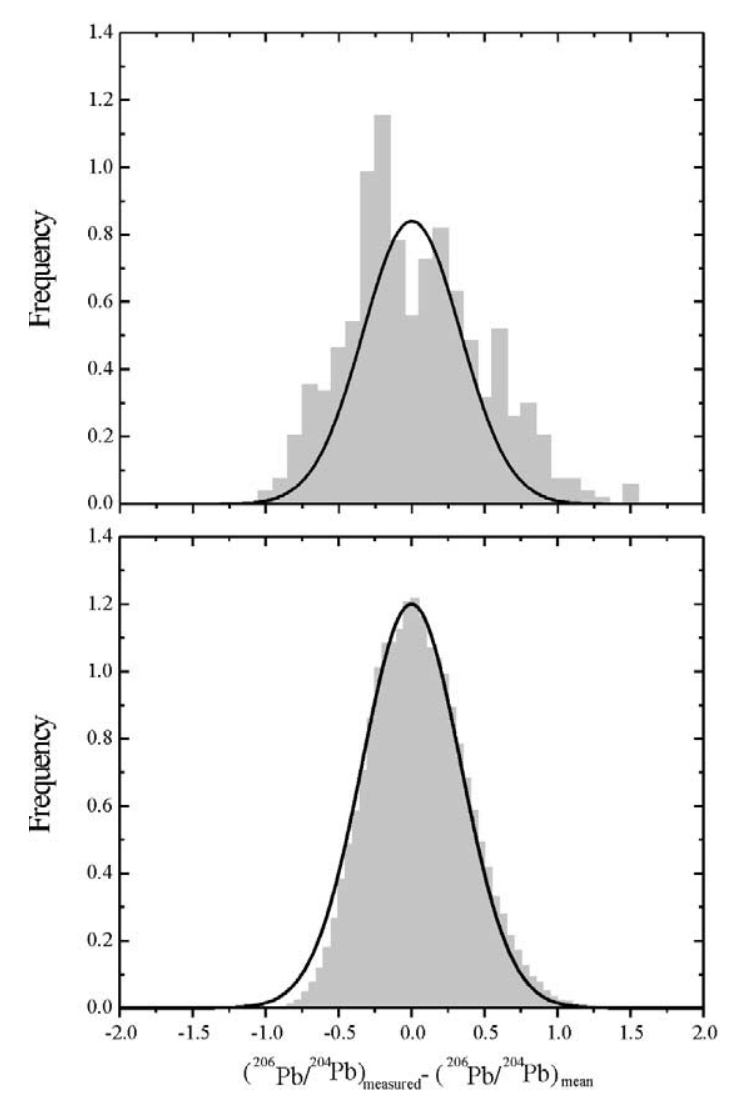

Fig. 4. Self-convolution of the MAR ${ }^{206} \mathrm{~Pb} /{ }^{204} \mathrm{~Pb}$ distribution. Solid lines: Gaussian fits. (Top) The initial distribution. (Bottom) The self-convolved distribution. Both distributions are normalized so that they can be directly compared. The shape of the self-convolved distribution is substantially more Gaussian and its width a factor of $\sqrt{2}$ smaller than the width of the initial distribution. Notice the effectiveness with which a single self-convolution has removed the outliers present in the initial distribution.

underlying distribution of heterogeneities, the characteristic length scale of the heterogeneity, the degree(s) of partial melting (of the different lithologies) and the characteristic length scale of the volume sampled by partial melting. If a geochemical distribution departs from a Gaussian shape this is likely a result of the sampled mantle volume and/or degree of partial melting not being large enough compared with the maximum size, or integral scale [46], of the domains contributing to the heterogeneity. It should be pointed out that chaotic mixing and stirring does not necessarily, by itself, lead to Gaussian distributions $[2,46]$. 
Thus, the shapes and the different widths of the distributions in Fig. 2 are powerful manifestations of the nature of the sampling or homogenization process. Direct comparison between the distributions from these five key localities provide new insights into the debate about the origin of MORB and OIB and the roles of sampling vs. solid-state convection in homogenization.

\section{Producing geochemical heterogeneity in the upper mantle}

Geochemical heterogeneity is introduced into the mantle by the subduction of fluids, sediments, oceanic crust and lithosphere and by inefficient melt extraction. Other processes also generate a range of geochemical 'components' in the upper mantle including hydrothermal alteration [23], degassing, dehydration, and mantle metasomatism involving either hydrous or carbonate fluids [48]. All these processes redistribute (i.e. fractionate) trace elements between different minerals, fluids and melts, which in turn allows these components to evolve along divergent isotopic trajectories.

Apart from subduction zone processes, the volumetrically most important process for generating heterogeneity is partial melting, which takes place in a variety of different settings in the upper mantle. Partial melting generates geochemical dichotomy because different elements partition differently between the magma and the solid residue from which the magma formed, i.e. crystal-melt fractionation. Incompatible elements, such as $\mathrm{U}$, $\mathrm{Th}, \mathrm{Pb}, \mathrm{K}, \mathrm{Rb}, \mathrm{Sr}, \mathrm{Sm}, \mathrm{Nd}$, and $\mathrm{Re}$, partition preferentially into the magma, although to different degrees. As the radioactive isotopes among these elements decay (for example ${ }^{238} \mathrm{U} \rightarrow{ }^{206} \mathrm{~Pb}$ and ${ }^{87} \mathrm{Rb} \rightarrow{ }^{87} \mathrm{Sr}$ ) the daughter isotopic compositions of the basaltic component evolve to more radiogenic values. Conversely, the isotopic composition of the depleted solid residue changes relatively little with time because of the lowered parent-to-daughter elemental ratio. On the other hand, depleted solid residues will have a range of isotopic compositions depending upon when the partial melting (i.e. depletion) event(s) took place. (Note that for the $\mathrm{Sm}-\mathrm{Nd}$ and the $\mathrm{Lu}-\mathrm{Hf}$ isotopic systems the evolution is opposite, because $\mathrm{Sm}(\mathrm{Lu})$ is less incompatible than $\mathrm{Nd}$ (Hf) [49].) Melts trapped in the upper mantle provide a pyroxenite component which can later be sampled at ridges and islands [50,51]. Events just prior to eruption, such as partial melting, blending of melts from different depths and degrees of partial melting, crystal fractionation, contamination and magma chamber processes, can generate a spectrum of basalt chemistries, even from the same mantle (e.g. [19]). This includes the kinds of offsets observed in MORBs and OIBs. We ignore these complications here and focus on the sampling problem and the predictions of the CLT, with regard to the isotopic compositions of young oceanic basalts.

Oceanic plates, which include basalts (often hydrothermally altered), mafic cumulates and ultramafic cumulates overlying depleted harzburgitic rock, are constantly formed along the roughly $60000 \mathrm{~km}$ long mid-ocean spreading ridge system, under which the underlying mantle undergoes pressure-release partial melting down to depths of order $30-200 \mathrm{~km}$ in a region up to several hundred kilometers wide (e.g. [52]). This is the approximate size of the melting, or sampling, volume that we discuss. Before the oceanic plate is returned to the upper mantle in a subduction zone, it can accumulate pelagic and terrigenous sediments and the harzburgites become serpentinized. Hot (i.e. young) slabs of oceanic crust will not sink far into the mantle and are likely to reside in the shallow mantle after subduction. About $15 \%$ of the current surface area of the oceans is composed of young $(<20 \mathrm{Myr})$ lithosphere approaching trenches and in young backarc basins; roughly $0.2 \mathrm{~km}^{3} /$ year of material less than $20 \mathrm{Myr}$ old is currently entering trenches [53]. A similar area (plateaus, aseismic ridges) has thick crust. This young and thick-crust material will probably not subduct to great depths. It will warm up and thermally equilibrate on short time scales (roughly in the time it spends at the surface) and become neutrally buoyant. These subducted oceanic crustal materials contribute to the chemical and lithologic heterogeneity of the shallow mantle and can be sampled again by partial melting on a characteristic time scale of 1-2 
Gyr at leaky transform faults, extensional regions of the lithosphere and by migrating ridges. In contrast, very old and cold slabs of oceanic crust are more likely to sink deeper into the mantle, where they will reside for longer periods of time, before they can contribute to the partial melts generated in the shallow upper mantle [3]. However, even the thicker slabs contribute some of their sediments and fluids to the shallow mantle during subduction. Processes and materials in the mantle wedge, above the slab, also contribute to mantle heterogeneity. Thus, materials with a range of ages, compositions (i.e. melting points) and length scales constantly enter the shallow mantle. They end up at various depths and survive for various lengths of time.

\section{The statistical upper mantle assemblage}

Plate tectonics introduces heterogeneity into the mantle having dimensions typical of slabs, 6-10 $\mathrm{km}$ crust, up to $50 \mathrm{~km}$ depleted residuum and $100 \mathrm{~km}$ thermal lithosphere and slab segments (e.g. [3]). As a slab sinks into the upper mantle it may become deformed, folded, stretched, thinned and broken up by convection if shear stresses, stress gradients and Rayleigh numbers are high. Typical Rayleigh numbers used in simulations of mantle convection and mixing are on the order of $10^{7}-10^{9}$, which would lead to chaotic or turbulent convection, rapid mixing and equilibration of subducted materials [1,2]. However, these estimates do not fully take into account the effects of plates, continents, pressure and phase changes, and potentially layered convection. Plate tectonics, strong lithosphere, deep continental roots, pressure effects on thermal properties such as viscosity, thermal expansion and conductivity, phase changes (such as spinel-postspinel), high Prandtl number, free-slip boundary conditions, and viscous layering are all phenomena that serve to organize and impede mantle flow, and shift the energy to longer wavelengths [54-56]. Chemical stratification and non-Newtonian rheology have similar effects. The net result is that the bulk of the upper mantle, away from boundary layers, is probably convecting slug- gishly, and passively, and is far from being wellmixed, chaotic or turbulent. The extreme stretching and thinning inferred for tectonically emplaced peridotites $[2,50,57]$ may occur in narrow mechanical boundary layers, but is unlikely to characterize the bulk of the upper mantle. In addition, convective stirring takes time and heterogeneities are constantly being introduced into the shallow mantle. In the absence of partial melting, crustal materials are not easily equilibrated with the materials into which they are subducted, because diffusive equilibration is extremely sluggish in solids [58]. Crustal materials and depleted residues of different ages are mechanically juxtaposed, but not chemically mixed or vigorously stirred [3]. The resulting state of the upper mantle is a highly heterogeneous assemblage of enriched and depleted lithologies representing a wide range in chemical composition and fertility and, as a result of different ages of these lithologies, widely different isotopic compositions [2]. Geochemical heterogeneity is present on length scales ranging from individual minerals (millimeter-size) to hundreds of kilometers, depending upon the partial melting history of the more depleted material, the subduction history, and the efficiency with which these lithologies have been mechanically blended [2]. We refer to this heterogeneity as the statistical upper mantle assemblage (SUMA).

The SUMA concept has obvious similarities to, but is also different from, many previous concepts introduced to explain perceived upper mantle homogeneity or to describe heterogeneity; such as the 'plum pudding' [59] or 'marble cake' models $[50,60]$. The latter concepts include the concept of a DMM reservoir as the convectively homogenized matrix (the pudding) into which enriched heterogeneities (the plums) are mixed. The source of the enrichment is often assumed to be from point sources of pollution, such as plumes or plumelets, originating below 'the convectively stirred upper mantle'. For example, E-MORB along the EPR is attributed to material flowing from Hawaii [29] and high ${ }^{3} \mathrm{He} /{ }^{4} \mathrm{He}$ spikes are traditionally attributed to deep plumes from an undegassed lower mantle reservoir [7]. The SUMA model replaces the concept of an effectively homogenized (by convection) DMM reservoir in the upper 
mantle. Indeed, a corollary of the SUMA model, and the CLT, is to abandon the concept of 'geochemical reservoirs' altogether and replace it with the concept of the statistical distribution, which is homogenized by the sampling process, primarily partial melting and blending of magmas. This was also argued by e.g. Helffrich and Wood [3] and Morgan and Morgan [22]. The complex version of the plum pudding model put forward by Morgan and Morgan [22] used six distinct components (primitive mantle, subducted MORB, subducted continental crust, subducted OIB, OIB residue, and MORB residue) to represent the various possible mantle components. In this model, recycled components are immediately averaged with the corresponding components already in the mantle [22]. Thus, in effect, this plum pudding model operates with six evolving mantle components that individually are represented by a single composition at any given point in time. In contrast, in the SUMA model, recycled components are not equilibrated with other components until they become involved in a partial melting (i.e. sampling) event $[2,3]$. Thus, recycled components maintain both their compositional spectrum and their age distribution. This aspect of the SUMA model is similar to the model by Kellogg et al. [2] and Helffrich and Wood [3], which we believe is a more realistic approach that leads to a larger degree of geochemical heterogeneity to be sampled in partial melting events. Convective stirring does not have to be particularly efficient as long as the scale of the heterogeneity is comparable to the scale of sampling, by partial melting. Models of convective mixing generally assume whole mantle convection and vigorous or chaotic convection (summarized in e.g. [1]).

In contrast to plum pudding, marble cake, plumelets and veined mantle models we have in mind chemical or lithologic heterogeneity of dimensions of $10^{2}-10^{5} \mathrm{~m}$, superposed on longer-wavelength heterogeneities (not averaged out by individual volcanoes), of hundreds to thousands of kilometers. These length scales $\left(10^{2}-10^{5} \mathrm{~m}\right)$ are introduced by recycling and plate tectonics and are not removed efficiently by diffusion, stretching-thinning, or mantle convection. Helffrich and Wood [3] summarized seismic evidence for similar length scale $(<10 \mathrm{~km})$ compositional heterogeneities in the lower mantle; shallow recycling is likely to make the upper mantle substantially more heterogeneous.

The shorter length scales are the dimensions of mantle wedges, slabs, magma chambers, and melting zones beneath ridges and volcanoes. The larger length scales are the dimensions of continents, island arcs and narrow oceans. Inhomogeneities of grain and vein scale, dikes and sills, i.e. the marble cake structure with characteristic heterogeneity length scales of less than $\sim 10 \mathrm{~m}$ [50], yield homogeneous basalts when sampled by partial melting over the length scales $(10-100 \mathrm{~km})$ characterizing mid-ocean ridges and hotspots through a typical volcanic plumbing system.

In the SUMA model, no genetic distinction is made between the mantle source region for MORB and OIB (see also [50]). Differences between these two types of oceanic basalt reflect different degrees of sampling of the underlying distribution of heterogeneities and the exact statistical nature of SUMA in different regions of the upper mantle. SUMA does not preclude the existence of large-scale heterogeneity or regional differences, such as the DUPAL anomaly [9], that are intrinsic to plate tectonics and the history of subduction and ridge processing. Instead, SUMA can be considered the moderately short-wavelength background heterogeneity onto which long-wavelength heterogeneity is imposed by the plate tectonic cycle. Large-scale heterogeneity is lateral or regional [3], potentially with a component of radial stratification. The three-dimensional properties of SUMA can, in principle, be random, organized or represent radial stratification, or be a combination. Seismic data utilizing anisotropy, scattering and attenuation may constrain the nature of the heterogeneity.

\section{Producing isotopically homogeneous basalts}

The primary cause of terrestrial volcanism is pressure-release melting of passively upwelling mantle [50,51,59,61-63]. Different lithologies in the upper mantle have different major element and mineral compositions and melt at different 
pressure and temperature conditions $[22,30,59,63]$. Melts migrate upwards, often in melt conduits, and often out of equilibrium with the surrounding host rocks (e.g. [64]). At shallower depths, i.e. lower pressure and temperature conditions, the melts coagulate, blend, partially crystallize and are finally erupted or intruded into cold crust and lithosphere. In some environments, melts pond, mix, fractionate and evolve beneath the crust or lithosphere [19]. As discussed above, the isotopic distributions among oceanic basalts that form as a blend of contributions from the various mantle components will approach normal distributions as predicted by the CLT. Thus, the 'SUMA' acronym also captures this important process: sampling upon melting and averaging. The degree to which the underlying mantle heterogeneities are averaged out in the resulting basalt, i.e. the width of the resulting normal distribution, depends on three factors: (1) the degree of partial melting, (2) the characteristic length scale on which melting takes place, and (3) the width of the underlying distribution of geochemical heterogeneity. We can crudely attempt to quantify this as:

$\sigma_{\mathrm{MEAS}}=\frac{\sigma_{\mathrm{UM}}}{\sqrt{M}}$,

where $\sigma_{\text {MEAS }}$ is the measured width of the obtained Gaussian distribution, $\sigma_{\mathrm{UM}}$ is a measure of the width of the underlying distribution of geochemical heterogeneity in the upper mantle, and:

$M \propto\left(\frac{L}{L_{\mathrm{HET}}}\right)^{3}\left(\frac{F}{F_{\mathrm{MIN}}}\right)$

is the 'effective melt product', where $L$ is the characteristic length scale of the mantle region undergoing partial melting, and $F$ the degree of partial melting (i.e. the mass of generated melt per unit mass of source rock). $L_{\mathrm{HET}}$ and $F_{\mathrm{MIN}}$ are the characteristic length scale of the underlying geochemical heterogeneity and minimum degree of partial melting that will produce enough accessible basalt, respectively. For practical purposes $F_{\text {MIN }}$ can be set to about 0.01 . The maximum degree of partial melting is around $F_{\mathrm{MAX}}=0.20$; although this is likely to be produced in stages, with small-degree melts from depth or from the wings of the magma chamber aggregating with larger-degree, shallow melts from different lithologies $[51,65,66]$.

The upper mantle is strongly anisotropic and attenuating to seismic waves (e.g. [19,67]). This is usually attributed to the flow of olivine crystals and the presence of a small melt fraction, but the scale lengths can not be determined with standard long-wavelength seismic waves. The heterogeneities could be grain-sized or slab-sized. However, the characteristic length scale of mantle heterogeneity can be constrained by seismic observations of scattered energy [3]. High-frequency techniques are available to map small-scale heterogeneities throughout the mantle $[3,68]$. These tools have been applied to the lower mantle and have yielded evidence for small-scale (less than $10 \mathrm{~km}$ ) bodies distributed throughout the lower mantle with wave speeds varying by more than $1 \%$ from that of the ambient material [3]. Such small-scale scatterers are inferred to be chemical heterogeneities introduced into the lower mantle by subduction of cold slabs [3]. Furthermore, measurements of precursors to multi-reflected core phases have shown that the upper $300 \mathrm{~km}$ of the mantle is complex, returning both coherent and incoherent reflections [69]. Seismic observations of high-frequency scattering in the upper mantle are increasing in number $[68,70-74]$. The intensity of scattering is pronounced in the $100-300 \mathrm{~km}$ depth interval and might indicate an even higher degree of chemical heterogeneity than in the lower mantle (Shearer, personal communication, 2003). The presence of buoyant or neutrally buoyant young slabs in the shallow mantle may be responsible for the anisotropy and high attenuation in the asthenosphere and the inference of melt zones in both the shallow and the deep upper mantle $[19,67,70,72]$. Typical dimensions of the most prominent scatterers in the upper mantle are about $5-10 \mathrm{~km}$ (Shearer, personal communication, 2003), which provides an estimate for $L_{\text {HET }}$. Helffrich and Wood [3] estimated that scatterers with dimensions smaller than about $4 \mathrm{~km}$ become seismically invisible on account of the attenuation of high-frequency body waves.

In the limit where $L=L_{\mathrm{HET}}$ and $F=F_{\mathrm{MIN}}$ we have $\sigma_{\mathrm{MEAS}}=\sigma_{\mathrm{UM}}$. For $L>L_{\mathrm{HET}}$ and $F>F_{\mathrm{MIN}}$ we get $\sigma_{\text {MEAS }}<\sigma_{\mathrm{UM}}$, i.e. high degree of partial 
melting in large regions of the upper mantle produces a narrow Gaussian distribution. With reasonable estimates of $L$ and $F$ from seismic observations, and spatial distributions and major element geochemistry of the basalts, the relative widths of the resulting Gaussian distributions provide a direct measure of the relative widths of the underlying distributions of heterogeneity in different regions of the upper mantle. Assuming that SUMA, to first order, provides a globally similar small- to moderate-scale distribution of heterogeneities everywhere in the upper mantle (i.e. $\sigma_{\mathrm{UM}}$ is relatively constant), we can immediately draw inferences about the average degree of partial melting and length scale involved in the melting process in each of the five regions included in this study. The EPR is by far the most rapidly spreading center, and is characterized by correspondingly small widths of the Gaussian distributions in Fig. 2. With EPR as the baseline, and the assumption of a globally constant $\sigma_{\mathrm{UM}}$, we compare the widths of the other distributions to those from EPR. For example, the ${ }^{206} \mathrm{~Pb} /{ }^{204} \mathrm{~Pb}$ distribution of MAR is slightly more than a factor of 2 wider than the ${ }^{206} \mathrm{~Pb} /{ }^{204} \mathrm{~Pb}$ of EPR (Fig. 2; Table 1). Under the above assumption this translates into $M_{\mathrm{EPR}} \approx 4 M_{\mathrm{MAR}}$. The SWIR ${ }^{206} \mathrm{~Pb} /{ }^{204} \mathrm{~Pb}$ distribution is broader yet and poorly defined (Fig. 2), consistent with the spreading rate of this ridge being ultraslow, with a small degree of partial melting and a short characteristic length scale of the sub-ridge melt system. The ${ }^{206} \mathrm{~Pb} /{ }^{204} \mathrm{~Pb}$ distributions of Iceland and Hawaii are similar and slightly broader than that of the EPR. This can either indicate that $M_{\text {HAWAII }} \approx M_{\text {ICELAND }} \leq$ $M_{\mathrm{EPR}}$, or that the width of the underlying distributions of $\mathrm{Pb}$ isotopic heterogeneity below Hawaii and Iceland are relatively smaller than under EPR. Qualitatively similar conclusions can be reached for the $\mathrm{Sr}$ and $\mathrm{Nd}$ isotopic systems among these five key regions. However, for the $\mathrm{Sr}$ and $\mathrm{Nd}$ isotopic systems there is additional useful information; significant differences between the mean (or mode) of the different distributions are observed. These differences may reflect inherent differences in the SUMA under each region. In this case, OIB isotopic compositions are not simply mixtures of a few endmember mantle components, but are instead consistent with each hotspot sampling recycled components that represent a unique distribution of chemical and isotopic compositions, which likely reflect alteration, subduction zone processing, metasomatism, and aging in the mantle (e.g. [1,3]). For example, the mean of the $\mathrm{Sr}$ isotopic distribution for EPR is less radiogenic than the mean for Hawaii (Fig. 2). Such differences might reflect compositional and age differences in the distribution of SUMA underneath each region, with SUMA underneath EPR being younger, on average, than underneath e.g. Hawaii. This is in line with Kellogg et al. [2] who concluded that the isotopic differences between MORB and OIB can not simply be due to systematic differences in sampled volume, but must also reflect compositional differences and/or melting processes. Specifically, Kel$\operatorname{logg}$ et al. [2] preferred to account for OIB isotopic compositions by mixing a larger fraction of undepleted, primitive material into their source regions.

In general, one does not expect the mantle to be chemically homogeneous at large scales, considering the effects of plate tectonics and recycling $[3,10]$. Melting anomalies can be caused, even with limited or no change in mantle temperature, by processing or focusing of larger volumes of mantle through the melting zone as at a spreading ridge segment or at new rift, and/or by compositional variations such as more recycled basaltic crust or locally increased pyroxenite and/or water contents [30,51,62,75-77].

Model calculations show that whole mantle convective stirring is difficult to reconcile with geochemical and geophysical observations [1], unless the entire mantle is characterized by moderate- to small-scale chemical or lithological heterogeneities [3]. Several concepts have been proposed to resolve the apparent conflicts between observational constraints and theoretical interpretations. The suggestions include the presence of deeper layering, preservation of highly viscous blobs, core-mantle interactions, temporal variations in mantle dynamics, and a global transition zone water filter (summarized in $[1,15]$ ). These are all variants of the reservoir concept. Statistical theory has been used before in discussions of MORB and 
OIB differences (e.g. [2,8,14,78]). Previous models are well summarized by Allègre [78]: "The OIB isotopic compositions are far more dispersed than MORB compositions. If we discuss these in terms of variance, the global variance of isotopic ratios for OIB is three times larger than the corresponding global variance of MORB [79]. This certainly corresponds with the fact that the MORB came from a well-stirred reservoir, while OIB came from a much less mixed reservoir [8]. A heterogeneous boundary layer (at $400 \mathrm{~km}$ depth) would certainly meet this observation".

The SUMA concept breaks with this reservoir tradition. The combination of plate tectonics, recycling, passive convection (i.e. ineffective stirring), and mantle heterogeneity with sampling theory is central to our model.

\section{Conclusions}

Intrinsic heterogeneity in the upper mantle is implied by plate tectonic processes and geochemical sampling. Recycling of crustal materials is likely the main process contributing to the upper mantle heterogeneity $[1-4,23,80]$. Much of this recycling is shallow and involves oceanic crust that was young upon subduction. This buoyant material has characteristic length scales of $10^{2}-10^{5} \mathrm{~km}$ and can exist for long periods of time in the shallow mantle without being equilibrated or reduced to sub-meter-sized veins, lamellae, or plums, by chaotic or turbulent convection and diffusion. Older thicker plates can sink deeper, but they also eventually become part of the upper mantle heterogeneity [3]. The homogeneous nature of MORB can be accomplished either by long-term convective stirring and mixing of the mantle source, if the convection is sufficiently vigorous $[2,14,50]$, or by homogenization near the extraction site by the sampling process, primarily partial melting and magma mixing [3]. The near-Gaussian distributions of $\mathrm{Pb}, \mathrm{Sr}$, and $\mathrm{Nd}$ isotopic variability observed in key MORB and OIB sample suites provide a powerful manifestation of the nature of the homogenization of a strongly heterogeneous upper mantle, as predicted by the central limit theorem. We refer to the underlying hetero- geneity of the mantle source as the statistical upper mantle assemblage and the primary sampling process as sampling upon melting and averaging. Thus, the 'SUMA' acronym captures both the nature of the heterogeneity and the process for averaging it out by sampling. The SUMA concept is different from the layered mantle and reservoir models, and the convective mixing models. It goes against the notion of a homogeneous or well-stirred DMM reservoir in the upper mantle, which is an assumption in many previous models. This has been called 'the convecting upper mantle', shorthand for a well-stirred, homogeneous reservoir. The SUMA model is similar to the model of mantle heterogeneity described by Morgan and Morgan [22] and Helffrich and Wood [3] and studied quantitatively by e.g. Kel$\operatorname{logg}$ et al. [2]. However, the homogenization scheme used by Kellogg et al. is long-term convective stirring, whereas we focus on homogenization during sampling, by partial melting and magma mixing [3].

In the SUMA model no genetic distinction is made between the mantle source region for MORB and OIB. Differences between these two types of oceanic basalt reflect different degrees of sampling and homogenization, and the exact statistical nature, of SUMA in different regions of the upper mantle, which is variable because of the recycling and tectonic history. Although we have focused on the homogenizing aspect of large-scale sampling we are also aware that mineralogical effects in sampling and magma chamber processes, such as crystal fractionation, can also introduce heterogeneity between basalts erupting from a common source. With the SUMA model we abandon the classical concept of 'geochemical reservoirs' [22], which usually involves the ad hoc assumption of storage of crustal materials in the lower mantle (e.g. [4,7-12]), and replace it with the notion of the statistical distributions of heterogeneity in the upper mantle [2,3,22].

Multiple scale heterogeneities in the upper mantle, sampled differently, not only can explain the statistical properties of oceanic basalts but may also be responsible for melting anomalies themselves, along the global ridge system and elsewhere. Shallow chemical heterogeneities com- 
prised of recycled oceanic crust or lithosphere can cause topographic and crustal thickness anomalies, because of fertility and melting point variations, without substantial thermal anomalies (e.g. $[30,75,76])$.

Isotopic distributions, such as those depicted in Fig. 2, and modeled by Kellogg et al. [2], coupled with systematic geophysical studies of key regions along the mid-oceanic ridge system and at oceanic islands, to constrain the average degree and depth of partial melting and the linear dimensions of the region undergoing melting, provide a promising avenue for quantifying upper mantle heterogeneity and, in the process, unifying geochemical and geophysical observations.

Scattering of high-frequency seismic waves [3] is one way to test the hypothesis that ubiquitous crustal- and slab-scale heterogeneities exist in the shallow oceanic mantle. The anisotropy and anelasticity of the asthenosphere is consistent with such a structure (e.g. [19,67]).

\section{Acknowledgements}

We are grateful to Norm Sleep, Bob Coleman, Ron Bracewell, George Thompson, Simon Klemperer, Robert Frei, James Kellogg, and John Mahoney for encouraging discussions. Dean Presnall and an anonymous reviewer are thanked for constructive criticism that helped improve the manuscript. A.M. is grateful for support through NSF Award EAR-0309414.[BW]

\section{Appendix}

$\begin{array}{ll}\text { Arithmetic mean }(\bar{x}) & =\frac{1}{N} \sum x_{i} \\ \text { Harmonic mean } & =\left(\frac{1}{N} \sum \frac{1}{x_{i}}\right)^{-1} \\ \text { Geometric mean } & =\sqrt[N]{x_{1} \cdot x_{2} \cdot \ldots \cdot x_{N}} \\ \text { Standard deviation }(\sigma) & =\frac{1}{N} \sqrt{N \sum\left(x_{i}\right)^{2}-\left(\sum x_{i}\right)^{2}} \\ \text { Skewness } & =\frac{1}{N} \sum\left(x_{i}-\bar{x}\right)^{3} \\ \text { Excess kurtosis } & =\frac{1}{N} \sum\left(\frac{x_{i}-\bar{x}}{\sigma}\right)^{4}-3\end{array}$

\section{References}

[1] P.E. van Keken, E. Hauri, C.J. Ballentine, Mantle mixing: The generation, preservation, and destruction of chemical heterogeneity, Annu. Rev. Earth Planet. Sci. 30 (2002) 493-525.

[2] J.B. Kellogg, S.B. Jacobsen, R.J. O'Connell, Modeling the distribution of isotopic ratios in geochemical reservoirs, Earth Planet. Sci. Lett. 204 (2002) 183-202.

[3] G.R. Helffrich, B.J. Wood, The Earth's mantle, Nature 412 (2001) 501-507.

[4] A.W. Hofmann, Mantle geochemistry: the message from oceanic volcanism, Nature 385 (1997) 219-229.

[5] B. Dupre, B. Lambret, D. Rousseau, C.J. Allègre, Limitation on the scale of mantle heterogeneity under oceanic ridges, Nature 294 (1981) 552-554.

[6] J.D. Macdougall, G.W. Lugmair, Extreme isotopic homogeneity among basalts fron the southern East Pacific Rise: mantle or mixing effect?, Nature 313 (1985) 209-211.

[7] D.W. Graham, Noble gas isotope geochemistry of midocean ridge and ocean island basalts: Characterization of mantle source reservoirs, in: D. Porcelli, C.J. Ballentine, R. Wieler (Eds.), Noble Gases in Geochemistry and Cosmochemistry, 47, Geochemical Society and American Society of America, Washington, DC, 2002, pp. 247-315.

[8] C.J. Allègre, D.L. Turcotte, Geodynamic mixing in the mesosphere boundary layer and the origin of oceanic islands, Geophys. Res. Lett. 12 (1985) 207-210.

[9] S.R. Hart, Heterogeneous mantle domains: signatures, genesis and mixing chronologies, Earth Planet. Sci. Lett. 90 (1988) 273-296.

[10] A. Zindler, S. Hart, Chemical geodynamics, Annu. Rev. Earth Planet. Sci. 14 (1986) 493-571.

[11] S.R. Hart, E.H. Hauri, L.A. Oschmann, J.A. Whitehead, Mantle plumes and entrainment: Isotopic evidence, Science 256 (1992) 517-520.

[12] B.B. Hanan, D.W. Graham, Lead and helium isotope evidence from oceanic basalts for a common deep source of mantle plumes, Science 272 (1996) 991-995.

[13] L.H. Kellogg, Mixing in the mantle, Annu. Rev. Earth Planet. Sci. 20 (1992) 365-388.

[14] C.J. Allègre, E. Levin, Isotopic systems and stirring times of the Earth's mantle, Earth Planet. Sci. Lett. 136 (1995) 629-646.

[15] D. Bercovici, S.-I. Karato, Whole-mantle convection and the transition-zone water filter, Nature 425 (2003) 39-44.

[16] D.L. Anderson, Phase changes in the upper mantle, Science 157 (1967) 1165-1173.

[17] B. Hamelin, C.J. Allègre, Large scale regional units within the depleted upper mantle: $\mathrm{Pb}-\mathrm{Sr}-\mathrm{Nd}$ study of the southwestern Indian Ridge, Nature 315 (1985) 196-199.

[18] F. Albarede and R.D. van der Hilst, New mantle convection model may reconcile conflicting evidence, EOS Trans. AGU 80 (1999) 535-539.

[19] D.L. Anderson, Theory of the Earth, Blackwell Scientific, Boston, MA, 1989, 366 pp.

[20] R. Batiza, Inverse relationship between $\mathrm{Sr}$ isotope diver- 
sity and rate of oceanic volcanism has implications for mantle heterogeneity, Nature 309 (1984) 440-441.

[21] J.G. Fitton, H.M. Dunlop, The Cameroon line, West Africa, and its bearing on the origin of oceanic and continental alkali basalt, Earth Planet. Sci. Lett. 72 (1985) 23-38.

[22] J.P. Morgan, W.J. Morgan, Two-stage melting and the geochemical evolution of the mantle: a recipe for mantle plum-pudding, Earth Planet. Sci. Lett. 170 (1999) 215239.

[23] J.M. Eiler, P. Schiano, N. Kitchen, E.M. Stolper, Oxygenisotope evidence for recycled crust in the sources of midocean-ridge basalts, Nature 403 (1999) 530-534.

[24] J.J. Mahoney, D.W. Graham, D.M. Christie, K.T.M. Johnson, L.S. Hall, D.L. Vonderhaar, Between a hotspot and a coldspot: Isotopic variation in the Southeast Indian Ridge asthenosphere, $86^{\circ} \mathrm{E}-118^{\circ} \mathrm{E}$, J. Petrol. 43 (2002) 1155-1176.

[25] J.I. Wendt, M. Regelous, Y. Niu, R. Hekinian, K.D. Collerson, Geochemistry of lavas from the Garrett Transform Fault: insights into mantle heterogeneity beneath the eastern Pacific, Earth Planet. Sci. Lett. 173 (1999) 271-284.

[26] A.E. Saal, E.H. Hauri, C.H. Langmuir, M.R. Perfit, Vapour undersaturation in primitive mid-ocean-ridge basalt and the volatile content of Earth's upper mantle, Nature 419 (2002) 451-455.

[27] A. Zindler, H. Staudigel, R. Batiza, Isotope and trace element geochemistry of young Pacific seamounts: implications for the scale of upper mantle heterogeneity, Earth Planet. Sci. Lett. 70 (1984) 175-195.

[28] Y. Niu, R. Batiza, Trace element evidence from seamounts for recycled oceanic crust in the Eastern Pacific mantle, Earth Planet. Sci. Lett. 148 (1997) 471-483.

[29] Y. Niu, K.D. Collerson, R. Batiza, J.I. Wendt, M. Regelous, Origin of enriched-type mid-ocean ridge basalt at ridges far from mantle plumes: The East Pacific Rise af $11^{\circ} 20^{\prime}$ N, J. Geophys. Res. 104 (1999) 7067-7087.

[30] Y. Niu, D. Bideau, R. Hekinian, R. Batiza, Mantle compositional control on the extend of mantle melting, crust production, gravity anomaly, ridge morphology, and ridge segmentation: a case study at the Mid-Atlantic Ridge 33-35 ${ }^{\circ}$ N, Earth Planet. Sci. Lett. 186 (2001) 383-399.

[31] Y. Niu, M. Regelous, I.J. Wendt, R. Batiza, M.J. O’Hara, Geochemistry of near-EPR seamounts: importance of source vs. process and the origin of enriched mantle component, Earth Planet. Sci. Lett. 199 (2002) 327-345.

[32] D.J. Fornari, M.R. Perfit, K.F. Allan, R. Batiza, R. Haymon, A. Barone, W.B.F. Ryan, T. Smith, T. Simkin, M.A. Luckman, Geochemical and structural studies of the Lamont seamounts: seamounts as indicators of mantle processes, Earth Planet. Sci. Lett. 89 (1988) 63-83.

[33] M. Regelous, Y. Niu, J.I. Wendt, R. Batiza, A. Greig, K.D. Collerson, Variations in the geochemistry of magmatism on the East Pacific Rise at $10^{\circ} 30^{\prime} \mathrm{N}$ since $800 \mathrm{ka}$, Earth Planet. Sci. Lett. 168 (1999) 45-63.
[34] A.E. Saal, S.R. Hart, N. Shimizu, E.H. Hauri, G.D. Layne, $\mathrm{Pb}$ isotopic variability in melt inclusions from oceanic island basalts, Polynesia, Science 282 (1998) 14811484.

[35] K. Burton, P. Schiano, J.-L. Birck, C.J. Allègre, Osmium isotope disequilibrium between mantle minerals in a spinel-lherzolite, Earth Planet. Sci. Lett. 172 (1999) 311322.

[36] I.J. Parkinson, C.J. Hawkesworth, A.S. Cohen, Ancient mantle in a modern arc: Osmium isotopes in Izu-BoninMariana forearc peridotites, Science 281 (1998) 20112013.

[37] A. Meibom, R. Frei, Evidence for an ancient osmium isotopic reservoir in Earth, Science 296 (2002) 516-518.

[38] A. Meibom, N.H. Sleep, C.P. Chamberlain, R.G. Coleman, R. Frei, M.T. Hren, J.L. Wooden, Re-Os isotopic evidence for long-lived heterogeneity and equilibrium processes in Earth's upper mantle, Nature 419 (2002) 705708 .

[39] L. Reisberg, A. Zindler, Extreme isotopic variability in the upper mantle: evidence from Ronda, Earth Planet. Sci. Lett. 81 (1986) 29-45.

[40] V.J.M. Salters, B.J.B. Dick, Mineralogy of the mid-oceanridge basalt source from neodymium isotopic composition of abyssal peridotites, Nature 418 (2002) 68-72.

[41] B. Hamelin, C.J. Allègre, Lead isotope study of orogenic lherzolite massifs, Earth Planet. Sci. Lett. 91 (1988) 117 131.

[42] D.W. Graham, J.E. Lupton, F.J. Spera, D.M. Christie, Upper-mantle dynamics revealed by helium isotope variations along the southeast Indian Ridge, Nature 409 (2001) 701-703.

[43] J. Korenaga, P.B. Kelemen, Major element heterogeneity in the mantle source of the North Atlantic igneous province, Earth Planet. Sci. Lett. 184 (2000) 251-268.

[44] M. Seyler, M. Cannat, C. Mevel, Evidence for major-element heterogeneity in the mantle source of abyssal peridotites from the Southwest Indian Ridge $\left(52^{\circ}\right.$ to $\left.68^{\circ} \mathrm{E}\right)$, Geochem. Geophys. Geosyst. 4 (2003) doi: 10.1029/ 2002GC000305.

[45] J. Mahoney, A.P. Le Roex, Z. Peng, R.L. Fisher, J.H. Natland, Southwestern limits of Indian Ocean ridge mantle and the origin of low ${ }^{206} \mathrm{~Pb} /{ }^{204} \mathrm{~Pb}$ mid-ocean ridge basalt: Isotopic systematics of the central Southwest Indian Ridge $\left(17^{\circ}-50^{\circ} \mathrm{E}\right)$, J. Geophys. Res. 97 (1992) 1977119790.

[46] B.I. Shraiman, E.D. Siggia, Scalar turbulence, Nature 405 (2000) 639-646.

[47] R.N. Bracewell, The Fourier Transform and its Applications, McGraw-Hill, New York, 2000, 616 pp.

[48] M.A. Menzies, C.J. Hawkesworth, Mantle metasomatism, in: Academic Press Geology Series, Academic Press, London, 1987, 472 pp.

[49] G. Faure, Principles of Isotope Geology, John Wiley and Sons, New York, 1986, 589 pp.

[50] C.J. Allègre, D.L. Turcotte, Implications of a two-component marble-cake mantle, Nature 323 (1986) 123-127. 
[51] M.M. Hirschmann, E.M. Stolper, A possible role for garnet pyroxenite in the origin of the 'garnet signature' in MORB, Contrib. Mineral. Petrol. 124 (1996) 185-208.

[52] D.C. Presnall, G.H. Gudfinnsson, M.J. Walter, Generation of mid-ocean ridge basalts at pressures from 1 to 7 GPa, Geochim. Cosmochim. Acta 66 (2002) 2073-2092.

[53] D.B. Rowley, Rate of plate creation and destruction: 180 Ma to present, GSA Bull. 114 (2002) 927-933.

[54] R. Trompert, U. Hansen, Mantle convection simulations with rheologies that generate plate-like behaviour, Nature 395 (1998) 686-689.

[55] H.-P. Bunge, M.A. Richards, The origin of large scale structure in mantle convection: effects of plate motions and viscosity stratification, Geophys. Res. Lett. 23 (1996) 2987-2990.

[56] U. Hansen, D.A. Yuen, S.E. Kroening, T.B. Larsen, Dynamical consequences of depth-dependent thermal expansivity and viscosity on mantle circulations and thermal structure, Phys. Earth Planet. Inter. 77 (1993) 205-233.

[57] L.H. Kellogg, D.L. Turcotte, Homogenization of the mantle by convective mixing and diffusion, Earth Planet. Sci. Lett. 81 (1986/87) 371-378.

[58] A.W. Hofmann, S.R. Hart, An assessment of local and regional isotopic equilibrium in the mantle, Earth Planet. Sci. Lett. 38 (1978) 44-62.

[59] N. Sleep, Tapping of magmas from ubiquitous mantle heterogeneities: An alternative to mantle plumes?, J. Geophys. Res. 89 (1984) 10029-10041.

[60] A. Prinzhofer, E. Lewin, C.J. Allègre, Stochastic melting of the marble cake mantle: evidence from local study of the East Pacific Rise at $12^{\circ} 50^{\prime} \mathrm{N}$, Earth Planet. Sci. Lett. 92 (1989) 189-206.

[61] P.W. Reiners, Temporal-compositional trends in intraplate basalt eruptions: Implications for mantle heterogeneity and melting processes, Geochem. Geophys. Geosyst. 3 (2002) doi: 10.1029/2001GC000250.

[62] P.D. Asimow, C.H. Langmuir, The importance of water to oceanic mantle melting regimes, Nature 421 (2003) $815-820$.

[63] J.P. Morgan, Thermodynamics of presdure release melting of a veined plum pudding mantle, Geochem. Geophys. Geosyst. 2 (2001) doi: 10.1029/2000GC000049.

[64] P.B. Kelemen, M. Braun, G. Hirth, Spatial distribution of melt conduits in the mantle beneath oceanic spreading ridges: Observations from the Ingalls and Oman ophiolites, Geochem. Geophys. Geosyst. 1 (2000) doi: 0.1029/ 1999GC000012.

[65] M.J. O'Hara, Trace element geochemical effects of integrated melt extraction and 'shaped' melting regimes, J. Petrol. 36 (1995) 1111-1132.
[66] T. Plank, C.H. Langmuir, Effects of the melting regime on the composition of the oceanic crust, J. Geophys. Res. 97 (1992) 19749-19770.

[67] G. Ekstrom, A.M. Dziewonski, The unique anisotropy of the Pacific upper mantle, Nature 394 (1998) 168-172.

[68] L. Nielsen, H. Thybo, A.V. Egorkin, Constraints on reflective bodies below the 8 degrees discontinuity from reflectivity modelling, Geophys. J. Int. 145 (2001) 759770.

[69] J.H. Whitcomb, D.L. Anderson, Reflection of $\mathrm{P}^{\prime} \mathrm{P}^{\prime}$ seismic waves from discontinuities in the mantle, J. Geophys. Res. 75 (1970) 5713-5728.

[70] H. Thybo, E. Perchuc, The seismic $8^{\circ}$ discontinuity and partial melting in continental mantle, Science 275 (1997) 1626-1629.

[71] K. Fuchs, M. Tittgemeyer, T. Ryberg, F. Wenzel, W. Mooney, Global significance of a sub-Moho boundary layer (SMBL) deduced from high-resolution seismic observations, Int. Geol. Rev. 44 (2002) 671-685.

[72] L. Vinnik, V. Farra, Subcratonic low-velocity layer and flood basalts, Geophys. Res. Lett. 29 (2002) doi: 10.1029/ 2002 GL014064.

[73] M. Warner, J. Morgan, P. Barton, P. Morgan, C. Price, K. Jones, Seismic reflections from the mantle represent relict subduction zones within the continental lithosphere, Geology 24 (1996) 39-41.

[74] S. Van der Lee, G. Nolet, Seismic image of the subducted trailing fragments of the Farallon plate, Nature 386 (1997) 266-269.

[75] E. Bonatti, Not so hot 'hot spots' in the oceanic mantle, Science 250 (1990) 107-111.

[76] E. Bonatti, M. Ligi, D. Brunelli, A. Cipriana, P. Fabretti, V. Farrante, L. Gasperini, L. Ottolini, Mantle thermal pulses below the Mid-Atlantic Ridge and temporal variations in the formation of oceanic lithosphere, Nature 432 (2003) 499-505.

[77] G. Ito, J.J. Mahoney, Effects of variable melt productivity and active mantle upwelling on trace-element and isotopic composition of hot-spot magmas, EOS Trans. AGU 83, Fall Meeting Suppl. (2002) Abstract S71D-06.

[78] C.J. Allègre, The evolution of mantle mixing, Phil. Trans. R. Soc. London A 360 (2002) 2411-2431.

[79] C.J. Allègre, B. Hamelin, A. Provost, B. Dupre, Topology in isotopic multispace and origin of mantle chemical heterogeneities, Earth Planet. Sci. Lett. 81 (1987) 319337.

[80] J.D. Woodhead, M.T. McCullogh, Ancient seafloor signals in Pitcairn Island lavas and evidence for large amplitude, small length-scale mantle heterogeneities, Earth Planet. Sci. Lett. 94 (1989) 257-273. 